\title{
Linking Emergence of the Central Pacific EI Niño to the Atlantic Multidecadal Oscillation
}

\author{
Jin-Yi Yu,* Pei-Ken KaO, ${ }^{+}$Houk Paek, ${ }^{*}$ Huang-Hsiung Hsu, ${ }^{\#}$ Chin-wen Hung, ${ }^{@}$ Mong-Ming Lu, ${ }^{\&}$ \\ AND SOON-IL AN** \\ * Department of Earth System Science, University of California, Irvine, Irvine, California \\ ${ }^{+}$Department of Earth System Science, University of California, Irvine, Irvine, California, and Department of Atmospheric Sciences, \\ National Taiwan University, Taipei, Taiwan \\ \# Department of Atmospheric Sciences, National Taiwan University, and Research Center for Environmental Change, Academia Sinica, \\ Taipei, Taiwan \\ ${ }^{\circledR}$ Department of Geography, National Taiwan Normal University, Taipei, Taiwan \\ ${ }^{\&}$ Center for Research and Development, Central Weather Bureau, Taipei, Taiwan \\ ** Department of Atmospheric Sciences, Yonsei University, Seoul, South Korea
}

(Manuscript received 12 May 2014, in final form 6 October 2014)

\begin{abstract}
The ocean-atmosphere coupling in the northeastern subtropical Pacific is dominated by a Pacific meridional mode (PMM), which spans between the extratropical and tropical Pacific and plays an important role in connecting extratropical climate variability to the occurrence of El Niño. Analyses of observational data and numerical model experiments were conducted to demonstrate that the PMM (and the subtropical Pacific coupling) experienced a rapid strengthening in the early 1990s and that this strengthening is related to an intensification of the subtropical Pacific high caused by a phase change of the Atlantic multidecadal oscillation (AMO). This PMM strengthening favored the development of more central Pacific (CP)-type El Niño events. The recent shift from more conventional eastern Pacific (EP) to more CP-type El Niño events can thus be at least partly understood as a Pacific Ocean response to a phase change in the AMO.
\end{abstract}

\section{Introduction}

The center of warm anomaly associated with El Niño events has moved from the eastern Pacific (EP) to central Pacific (CP) in recent decades (Larkin and Harrison 2005; Yu and Kao 2007; Ashok et al. 2007; Kao and Yu 2009; Kug et al. 2009; Lee and McPhaden 2010; Yu and Giese 2013; Capotondi et al. 2013). The cause of this recent emergence of the CP El Niño is not yet known but could be a consequence of global warming (Yeh et al. 2009) or an expression of natural variability (McPhaden et al. 2011; Newman et al. 2011). The exact timing of this location shift has been suggested to be sometime between the 1980s (Ashok et al. 2007) and the beginning of the twenty-first century (Lee and McPhaden 2010). Yu et al. (2012) used three atmospheric and oceanic indices to argue that the location shift is most obvious around

Corresponding author address: Dr. Jin-Yi Yu, Department of Earth System Science, University of California, Irvine, Irvine, CA 92697-3100.

E-mail: jyyu@uci.edu a period centered on 1993. This early-1990s timeframe is close to the time when the Atlantic multidecadal oscillation (AMO; Schlesinger and Ramankutty 1994; Kerr 2000) changed its phase. It has been suggested that the AMO can impact climate not only within the Atlantic basin but also across the Northern Hemisphere, including the Pacific Ocean (e.g., Zhang and Delworth 2007). The possible linkage between the recent emergence of the CP El Niño and the AMO is examined in this study.

We begin describing a possible chain of events resulting in a shift in the location of El Niño by focusing on variations in the strength of the Pacific meridional mode (PMM; Chiang and Vimont 2004), which is the key ocean-atmosphere coupling mode of the subtropical Pacific and plays a crucial role in connecting extratropical climate variability to El Niño generation (e.g., Anderson 2003; Chiang and Vimont 2004; Alexander et al. 2006, 2010; Chang et al. 2007). The PMM is characterized by covariability in sea surface temperatures (SSTs) and surface winds over the northeastern subtropical Pacific. Wind fluctuations associated with 
extratropical atmospheric variability, in particular the North Pacific Oscillation (NPO; Walker and Bliss 1932; Rogers 1981), induce SST anomalies in the subtropical Pacific via evaporation anomalies. The SST anomalies then modify the winds via convection. This windevaporation-SST (WES) feedback mechanism (Xie and Philander 1994) prolongs and extends the atmosphereinduced SST anomalies equatorward and westward from their generation location in the northeastern subtropical Pacific toward the tropical central Pacific to form the spatial pattern of the PMM. The atmosphere-ocean coupling also sustains the PMM from boreal winter, when the extratropical atmospheric variability is strongest (e.g., Vimont et al. 2001, 2003), to the following seasons, which explains how the extratropical variability in winter can trigger the development of El Niño events in the following spring or summer.

More recently, the PMM and its associated subtropical coupling were suggested to play a particularly important role in exciting the CP El Niño (Yu and Kim 2011; Kim et al. 2012; Lin et al. 2014). In contrast to the conventional EP type of El Niño that is characterized by SST anomalies extending westward from the South American coast with decreasing amplitude, the CP El Niño has most of its SST anomalies confined around the international date line. While the generation of the EP El Niño involves traditional El Niño dynamics that emphasize equatorial Pacific thermocline variations (e.g., Suarez and Schopf 1988; Battisti and Hirst 1989; Jin 1997), the generation of the CP El Niño has been linked by some to forcing from the extratropical atmosphere (Yu and Kim 2011; Yu et al. 2011, 2012; Kim et al. 2012; Lin et al. 2014). The extratropical atmospheric forcing is suggested to penetrate into the tropical central Pacific through the PMM via the WES feedback mechanism. Since the CP El Niño has occurred more frequently in recent decades, it is natural to wonder whether the PMM has also experienced similar decadal variations and how these variations, if any, might be related to leading modes of decadal variability, including the AMO and the Pacific decadal oscillation (PDO; Mantua et al. 1997). Statistical analyses using observational and reanalysis data and numerical experiments using an atmospheric general circulation model (AGCM) coupled with a slab ocean were performed to answer these questions. It should be noted that zonal advection in the tropical Pacific has also been suggested to be important to the generation of CP El Niño events (e.g., Kug et al. 2009; $\mathrm{Yu}$ et al. 2010) and can extend the PMM-induced warming in the central Pacific eastward leading to EP El Niño events (e.g., Alexander et al. 2010). Nevertheless, a recent study reported that the PMM and its subtropical coupling seem more linked to the generation of the CP El Niño than to the EP El Niño in the multiple coupled GCM simulations (Lin et al. 2014). In this study, the possible role of zonal ocean advection is not examined.

\section{Datasets}

In this study, datasets used for analysis include the monthly 10-m winds and sea level pressure (SLP) from the National Centers for Environmental PredictionNational Center for Atmospheric Research (NCEPNCAR) reanalysis dataset (Kalnay et al. 1996) and SSTs from National Oceanic and Atmospheric Administration (NOAA) Extended Reconstructed Sea Surface Temperature dataset (ERSST; Smith et al. 2008). Specifically, data for the period 1948-2010 were analyzed. Monthly anomalies were obtained by removing the seasonal cycles and linear trends. To validate the results obtained from the NCEP-NCAR reanalysis, we also used the Twentieth Century Reanalysis (20CR; Compo et al. 2011) and the Japanese 55-year Reanalysis Project (JRA-55; Ebita et al. 2011).

Two indices for decadal variability modes were used in this study: the PDO index and the AMO index. The PDO index was defined as the leading principal component (PC) of an empirical orthogonal function (EOF) mode of monthly SST anomalies in the North Pacific (poleward of $20^{\circ} \mathrm{N}$ ) after removing the global-mean SST anomalies (Mantua et al. 1997). The AMO index was defined as the linearly detrended area-averaged SST anomalies over the North Atlantic $\left(0^{\circ}-70^{\circ} \mathrm{N}\right)$ (Enfield et al. 2001).

A set of the Atmospheric Model Intercomparison Project (AMIP; Gates et al. 1999) model output in phase 5 of the Coupled Model Intercomparison Project (CMIP5; Taylor et al. 2012) as summarized in Table 1 was also used to gain insight into the observational findings.

\section{Results}

To identify the PMM, a singular value decomposition (SVD; Bretherton et al. 1992) analysis was applied to the cross-covariance between SST and 10-m wind anomalies in the northeastern subtropical Pacific $\left(20^{\circ} \mathrm{S}-30^{\circ} \mathrm{N}\right.$, $175^{\circ} \mathrm{E}-95^{\circ} \mathrm{W}$ ). We removed the ENSO signals (regressions of SST and 10-m wind anomalies with an index of ENSO) from the original anomalies before the SVD analysis. Following Chiang and Vimont (2004), we chose to use the cold tongue index (CTI; SST anomalies averaged over $6^{\circ} \mathrm{S}-6^{\circ} \mathrm{N}, 180^{\circ}-90^{\circ} \mathrm{W}$ ) to remove the El Niño influence. It should be noted that this is not an optimal way to remove the ENSO signals. Compo and Sardeshmukh (2010) and Solomon and Newman (2012) 
have developed methods that can better remove the full spatial structure and evolution of the ENSO signals using a linear inverse modeling approach. Nevertheless, the domain of the CTI index covers not only the EP ENSO region (i.e., Niño-3 region) but also a large part of the CP ENSO region (i.e., Niño-4 region) and is suitable for the purpose of this study.

The leading SVD mode shown in Fig. 1a depicts the PMM's SST and wind anomaly patterns during the peak season of the PMM [i.e., March-May (MAM)]. The pattern is characterized by positive SST anomalies and southwesterly wind anomalies extending from the Baja California coast to the tropical central Pacific. The southwesterly wind anomalies represent a weakening of the climatological northeasterly trade winds in the northern subtropics and are collocated with positive SST anomalies because of the reduced surface evaporation associated with the weaker trade winds. A pair of PCs was also produced as part of the SVD analysis. The PCs represent the temporal variations of the PMM-associated SST and surface wind anomalies and are referred to, respectively, as the PMM SST and wind indices.

Since the PMM is a mode of coupled atmosphereocean variability, its strength can be represented by the correlation coefficient between the PMM SST and wind indices. This correlation during MAM is calculated using a 10-yr window running from 1948 to 2010. As shown in Fig. 1b, the correlation (i.e., the PMM strength) drops briefly around 1960, 1976, and 1993 to divide 1962-2004 into three periods: 1962-72 (period I), 197788 (period II), and 1993-2004 (period III). We only focus on the period from 1962, as the data prior to period I are too short. The PMM strength shows a stepwise increase, starting from a relatively weak state during periods I and II and then jumping to a strong state during period III. The mean correlation substantially increases from periods I and II ( 0.73 for both periods) to period III (0.86). With a stringent test, the difference in the mean PMM strength between period III and the other two periods passes the $90 \%$ confidence level using a one-tailed Student's $t$ test. The robustness of this early-1990s strengthening was validated by repeating the SVD and correlation analyses with two additional reanalysis products: the 20CR and JRA-55. A significant and similar early-1990s jump in the correlation was found in these two additional datasets (Figs. 1c,d). It is important to note that this early-1990s strengthening of the PMM coincides with the time when the El Niño was determined to shift from being predominantly of the EP type to being predominantly of the $\mathrm{CP}$ type ( $\mathrm{Yu}$ et al. 2012). Investigating the cause of this strengthening will help to understand why the CP El Niño has occurred more frequently in recent decades.
To understand why the PMM strength has varied, we examined in Fig. 2 the mean SLP and 10-m wind states during each of the three periods during the boreal winter-spring seasons [December-May (DJFMAM)]. These are the seasons when the PMM typically develops and peaks (e.g., Chiang and Vimont 2004). The SLP climatology in these seasons (Fig. 2a) is characterized by an Aleutian low over the North Pacific and a Pacific subtropical high over the eastern subtropics. The change in the mean SLP (color shading) from period I to II (Fig. 2b) is dominated by an intensification of the Aleutian low with a particular northwest-southeast orientation (highlighted by a red dashed line). This SLP change was accompanied by cyclonic wind anomalies (vectors). In contrast, the change in the mean SLP from period II to III (Fig. 2c) is dominated by a weakening of the Aleutian low and an intensification of the subtropical high. The intensified high is centered in the eastern Pacific and extends southwestward to the tropical central Pacific. This particular northeast-southwest orientation is highlighted in Fig. 2c by a red dashed line. The SLP change was accompanied by anticyclonic wind anomalies that strengthened the mean northeasterly trade winds. In the figure, we use a green contour to highlight the location of the PMM (i.e., Baja California to the tropical central Pacific) from Fig. 1a; it is clear that this region overlaps with the region where the most significant changes occur in the background trade winds and SLP from period II to III. This overlapping indicates that the SLP and trade wind changes are likely to affect the strength of the PMM. Although the mean SLP changes from period I to II also appear in the subtropical Pacific region (see Fig. 2b), they overlap only with the northern portion of the PMM region and are less likely to affect the strength of the PMM.

The significant changes in the subtropical high and its associated trade winds have important implications for the WES feedback mechanism that supports the PMM. The relationship between latent heat flux anomalies and surface wind anomalies is an important component of the WES feedback, which can be expressed by the following relationship according to Czaja et al. (2002) and Vimont et al. (2009):

$$
\frac{\delta \mathrm{LH}}{\delta u} \sim \frac{u}{\sqrt{u^{2}+w_{*}^{2}}}=\frac{1}{\sqrt{1+\left(\frac{w_{*}}{u}\right)^{2}}},
$$

where $\delta \mathrm{LH}$ is the latent heat flux variation caused by the zonal wind variation $(\delta u)$ for a given mean zonal wind state $(u)$ and turbulent background wind speed $\left(w_{*}\right)$. Here, for simplicity and explanatory purposes, we neglect the meridional wind in the equation. The efficiency 
TABLE 1. The 25 AMIP models used in this study

\begin{tabular}{|c|c|c|c|c|}
\hline & Model acronym & Model name & Modeling group & $\begin{array}{l}\text { No. of } \\
\text { ensemble } \\
\text { members }\end{array}$ \\
\hline 1 & ACCESS1.0 & $\begin{array}{l}\text { Australian Community Climate and } \\
\text { Earth-System Simulator, version } 1.0\end{array}$ & $\begin{array}{l}\text { Commonwealth Scientific and Industrial Re- } \\
\text { search Organisation (CSIRO) and Bureau of } \\
\text { Meteorology (BOM) }\end{array}$ & 1 \\
\hline 2 & ACCESS1.3 & $\begin{array}{l}\text { Australian Community Climate and } \\
\text { Earth-System Simulator, version } 1.3\end{array}$ & CSIRO and BOM & 2 \\
\hline 3 & BCC-CSM1.1 & $\begin{array}{l}\text { Beijing Climate Center, Climate } \\
\text { System Model, version } 1.1\end{array}$ & $\begin{array}{l}\text { Beijing Climate Center (BCC), China Meteo- } \\
\text { rological Administration }\end{array}$ & 3 \\
\hline 4 & BNU-ESM & $\begin{array}{l}\text { Beijing Normal University-Earth } \\
\text { System Model }\end{array}$ & $\begin{array}{l}\text { College of Global Change and Earth System } \\
\text { Science (GCESS), Beijing Normal University }\end{array}$ & 1 \\
\hline 5 & CanAM4 & $\begin{array}{l}\text { Canadian Fourth Generation Atmospheric } \\
\text { General Circulation Model }\end{array}$ & $\begin{array}{l}\text { Canadian Centre for Climate Modelling and } \\
\text { Analysis (CCCma) }\end{array}$ & 4 \\
\hline 6 & CCSM4 & Community Climate System Model, version 4 & NCAR & 4 \\
\hline 7 & CESM1 & Community Earth System Model, version 1 & NCAR & 2 \\
\hline 8 & CMCC-CM & $\begin{array}{l}\text { Centro Euro-Mediterraneo per I Cambiamenti } \\
\text { Climatici Climate Model }\end{array}$ & $\begin{array}{l}\text { Centro Euro-Mediterraneo sui Cambiamenti } \\
\text { Climatici (CMCC) }\end{array}$ & 3 \\
\hline 9 & CNRM-CM5 & $\begin{array}{l}\text { Centre National de Recherches Météorologiques } \\
\text { Coupled Global Climate Model, version } 5\end{array}$ & $\begin{array}{l}\text { Centre National de Recherches Météor- } \\
\text { ologiques (CNRM)/Centre Européen de } \\
\text { Recherche et de Formation Avancée en } \\
\text { Calcul Scientifique (CERFACS) }\end{array}$ & 1 \\
\hline 10 & CSIRO-Mk3.6.0 & $\begin{array}{l}\text { Commonwealth Scientific and Industrial } \\
\text { Research Organisation Mark 3.6.0 }\end{array}$ & $\begin{array}{l}\text { CSIRO in collaboration with Queensland } \\
\text { Climate Change Centre of Excellence } \\
\text { (QCCCE) }\end{array}$ & 4 \\
\hline 11 & FGOALS-g2 & $\begin{array}{l}\text { Flexible Global Ocean-Atmosphere-Land } \\
\text { System Model, gridpoint version } 2\end{array}$ & $\begin{array}{l}\text { State Key Laboratory of Numerical Modeling } \\
\text { for Atmospheric Sciences and Geophysical } \\
\text { Fluid Dynamics (LASG), Institute of Atmo- } \\
\text { spheric Physics (IAP), Chinese Academy of } \\
\text { Sciences }\end{array}$ & 1 \\
\hline 12 & FGOALS-s2 & $\begin{array}{l}\text { Flexible Global Ocean-Atmosphere-Land } \\
\text { System Model, second spectral version }\end{array}$ & LASG, IAP, Chinese Academy of Sciences & 3 \\
\hline 13 & GFDL CM3 & $\begin{array}{l}\text { Geophysical Fluid Dynamics Laboratory } \\
\text { Climate Model, version } 3\end{array}$ & $\begin{array}{l}\text { NOAA/Geophysical Fluid Dynamics } \\
\text { Laboratory (GFDL) }\end{array}$ & 2 \\
\hline 14 & GISS-E2-R & $\begin{array}{l}\text { Goddard Institute for Space Studies Model E2, } \\
\text { coupled with the Russell ocean model }\end{array}$ & $\begin{array}{l}\text { National Aeronautics and Space Administration } \\
\text { (NASA) Goddard Institute for Space Studies } \\
\text { (GISS) }\end{array}$ & 4 \\
\hline 15 & HadGEM2-A & $\begin{array}{l}\text { Hadley Centre Global Environment Model, } \\
\text { version 2-Atmosphere }\end{array}$ & $\begin{array}{l}\text { National Institute of Meteorological Research } \\
\text { (NIMR)/Korea Meteorological Administra- } \\
\text { tion (KMA) }\end{array}$ & 4 \\
\hline 16 & HIRAM-C180 & $\begin{array}{l}\text { High Resolution Atmospheric Model, } \\
180 \times 180 \text { gridpoint resolution }\end{array}$ & NOAA/GFDL & 3 \\
\hline 17 & INM-CM4 & $\begin{array}{l}\text { Institute of Numerical Mathematics } \\
\text { Coupled Model, version } 4\end{array}$ & Institute of Numerical Mathematics (INM) & 1 \\
\hline 18 & IPSL-CM5A-LR & $\begin{array}{l}\text { L'Institut Pierre-Simon Laplace Coupled } \\
\text { Model, version 5A, low resolution }\end{array}$ & L'Institut Pierre-Simon Laplace (IPSL) & 4 \\
\hline 19 & IPSL-CM5A-MR & $\begin{array}{l}\text { L'Institut Pierre-Simon Laplace Coupled } \\
\text { Model, version 5A, mid resolution }\end{array}$ & IPSL & 3 \\
\hline 20 & MIROC5 & $\begin{array}{l}\text { Model for Interdisciplinary Research on } \\
\text { Climate, version } 5\end{array}$ & $\begin{array}{l}\text { Japan Agency for Marine-Earth Science and } \\
\text { Technology, Atmosphere and Ocean Re- } \\
\text { search Institute (University of Tokyo), and } \\
\text { National Institute for } \\
\text { Environmental Studies }\end{array}$ & 2 \\
\hline 21 & MPI-ESM-LR & $\begin{array}{l}\text { Max Planck Institute Earth System Model, } \\
\text { low resolution }\end{array}$ & Max Planck Institute for Meteorology (MPI-M) & 3 \\
\hline 22 & MPI-ESM-MR & $\begin{array}{l}\text { Max Planck Institute Earth System Model, } \\
\text { medium resolution }\end{array}$ & MPI-M & 3 \\
\hline
\end{tabular}




\begin{tabular}{|c|c|c|c|c|}
\hline & Model acronym & Model name & Modeling group & $\begin{array}{l}\text { No. of } \\
\text { ensemble } \\
\text { members }\end{array}$ \\
\hline 23 & MRI-AGCM2H & $\begin{array}{l}\text { Meteorological Research Institute } \\
\text { Atmospheric General Circulation Model, } \\
\text { version } 2 \text { (high resolution) }\end{array}$ & Meteorological Research Institute (MRI) & 3 \\
\hline 24 & MRI-CGCM3 & $\begin{array}{l}\text { Meteorological Research Institute Coupled } \\
\text { Atmosphere-Ocean General Circulation } \\
\text { Model, version } 3\end{array}$ & MRI & 2 \\
\hline 25 & NorESM1-M & $\begin{array}{l}\text { Norwegian Earth System Model, version } 1 \\
\text { (intermediate resolution) }\end{array}$ & Norwegian Climate Centre (NCC) & 3 \\
\hline
\end{tabular}

of the WES feedback (i.e., $\delta \mathrm{LH} / \delta u$ ) can be affected by the ratio of the turbulent background wind to the mean zonal wind $\left(w_{*} / u\right)$ in the denominator on the RHS of the equation. According to the equation, the stronger the background wind $(u)$, the smaller the ratio and the larger the WES feedback efficiency. Physically, the WES feedback mechanism is known to work when the wind anomalies induced by convection are in a direction opposite to that of the mean winds (Xie 1999). In order for the WES feedback to work more efficiently, the mean wind $(u)$ should not change direction. However, the mean wind direction can be reversed by the background disturbances $\left(w_{*}\right)$. Therefore, the stronger the mean zonal wind $(u)$, the more easily the disturbance reversal
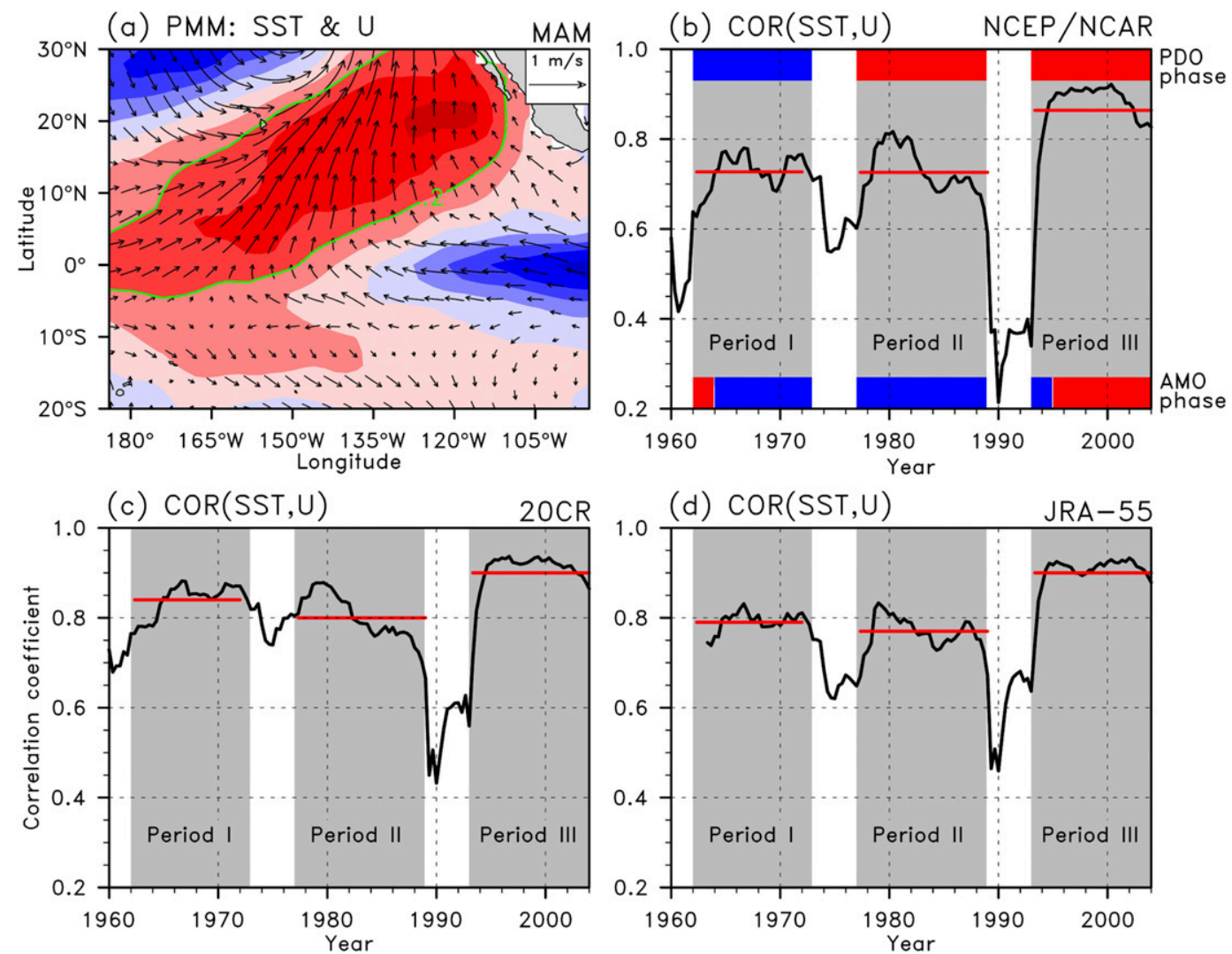

FIG. 1. (a) The leading SVD mode of SST (color shading) and 10-m wind (vectors) anomalies for the PMM in boreal spring (MAM). Red (blue) shading indicates positive (negative) values with an interval of $0.1^{\circ} \mathrm{C}$. The green contour is the $0.2^{\circ} \mathrm{C}$ isotherm representing the PMM region. (b) 10-yr running correlation coefficients between the PMM SST and wind indices. The red line indicates a mean of the correlation coefficients during each period. The gray shading is used to emphasize three different periods (1962-72,1977-88, and 1993-2004). The shadings at the top and bottom are the positive (red) and negative (blue) phases of the 10-yr low-pass-filtered PDO and AMO, respectively. (c),(d) As in (b), but for (c) 20CR and (d) JRA-55. 
(a) SLP : 1948-2010 climatology

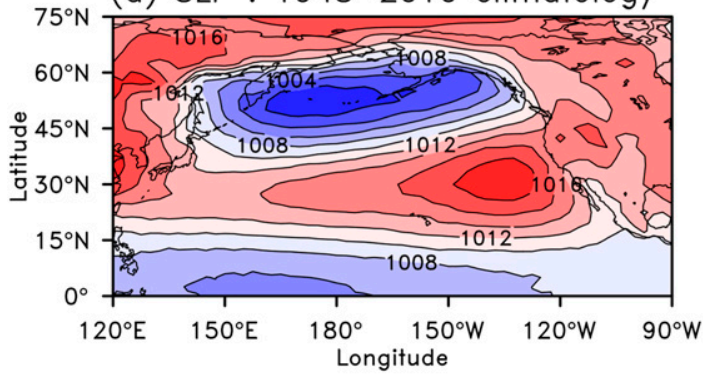

(b) SLP \& U: Period II - Period I

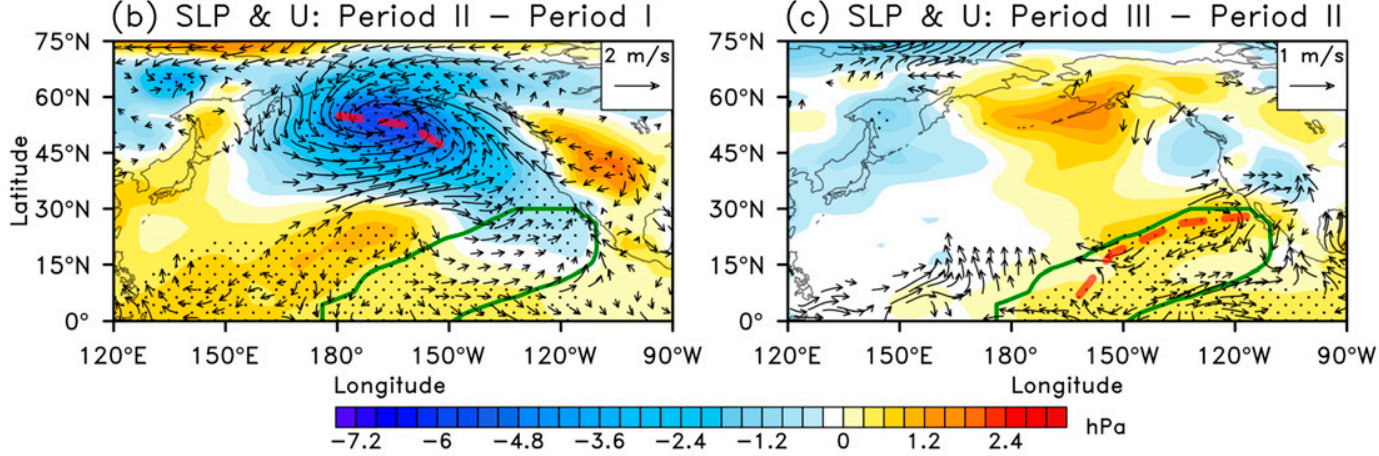

(d) Regressed SLP \& U onto PDO

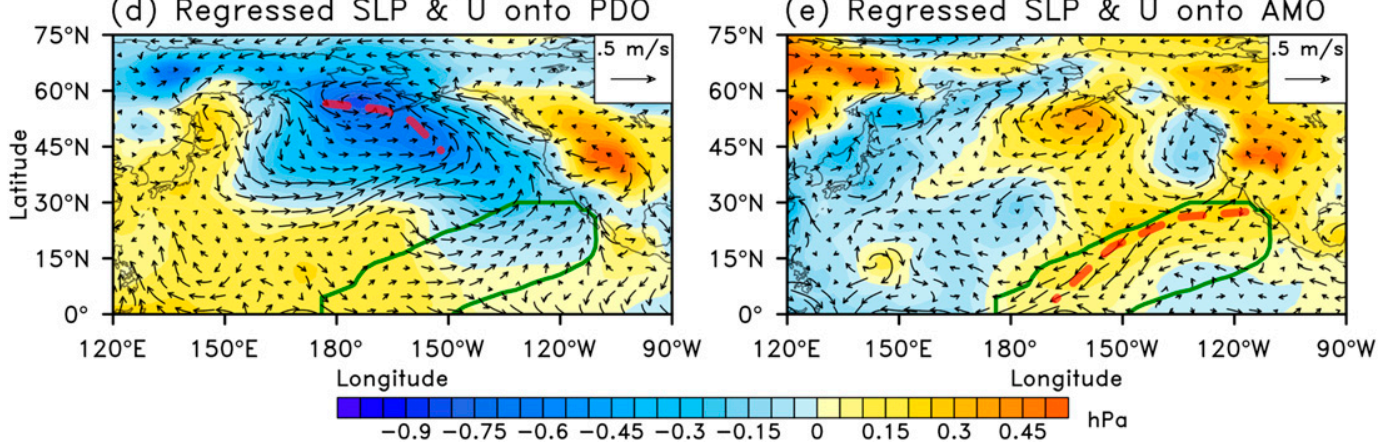

FIG. 2. (a) The winter-spring (DJFMAM) SLP climatology for the period 1948-2010. A contour interval is $2 \mathrm{hPa}$. (b) The differences of the DJFMAM-mean SLP (color shading) and 10-m winds (vectors) between period II (197788 ) and period I (1962-72). The dotted areas are where SLP differences are significant at the $95 \%$ level, and only winds exceeding the 95\% level are shown (using a two-tailed Student's $t$ test). (c) As in (b), but for the differences between period III (1993-2004) and period II. (d) The regressed DJFMAM SLP (color shading) and 10-m wind (vectors) anomalies onto the 10-yr low-pass-filtered standardized PDO index. (e) As in (d) but for the AMO index. The green contour is the PMM region defined in Fig. 1a. Red dashed lines highlight the orientations of the SLP differences and regressions.

of wind direction can be overcome to favor an efficient WES feedback. Since positive PMM SST anomalies typically induce southwesterly wind anomalies in its southwestern quadrant (Fig. 1a), the stronger the mean northeasterly trade winds the more efficient the WES feedback mechanism. Associated with the intensified Pacific high, the background trade winds in period III are stronger than in period II in both their zonal $(u)$ and meridional $(v)$ components. As shown in Fig. 3, the negative differences (meaning stronger easterly and northerly winds) are large over the northeastern subtropical Pacific in the west of the Baja California where the core region of the PMM is located. It should also be noted that the WES feedback is more sensitive to the zonal wind than meridional wind (Vimont et al. 2009). Our analyses suggest that the strengthened PMM in period III is a result of a stronger WES feedback mechanism associated with an intensified subtropical high and background trade winds.

The mean SLP changes between the periods can also affect the location of midlatitude jet stream, which controls the location of midlatitude synoptic-scale eddies. A more southward-located jet stream can steer more midlatitude eddies into the subtropics (i.e., increasing the 

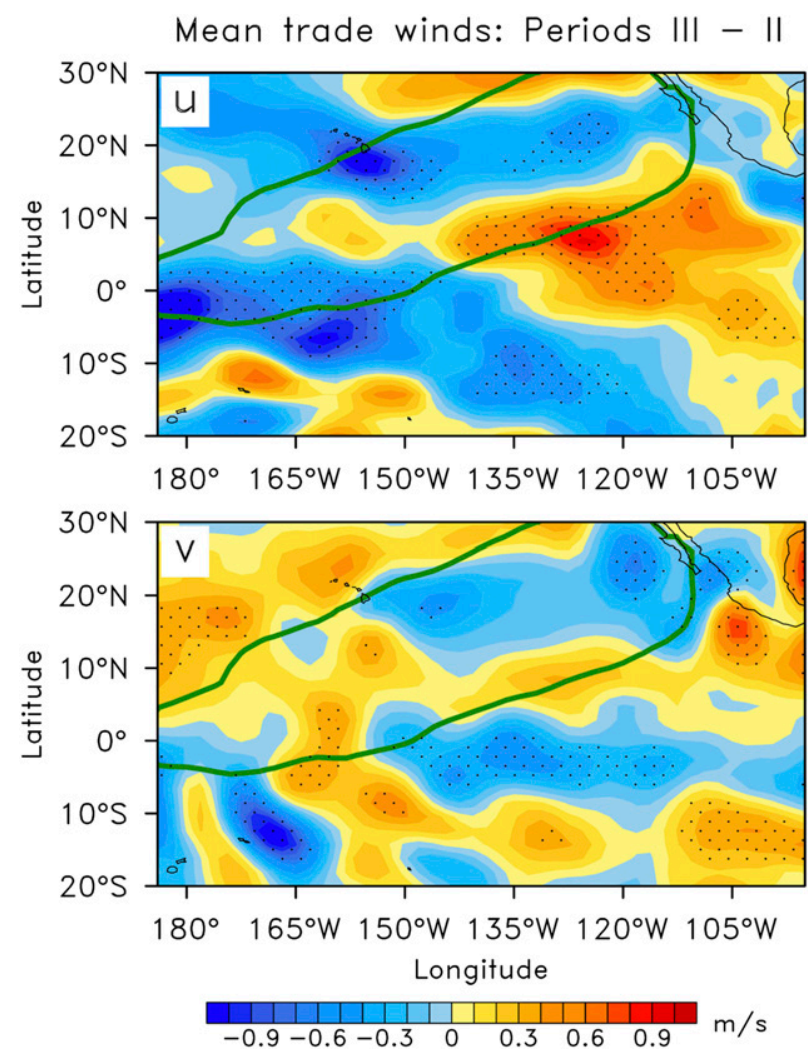

FIG. 3. The differences of the DJFMAM-mean background trade winds in the zonal and meridional directions ( $u$ and $v$, respectively) between periods III and II. The dotted areas are where the background wind differences are significant at the $95 \%$ level. The green contour indicates the PMM region.

background turbulence) to interrupt the WES feedback. In contrast, a more northward-located jet stream is likely to reduce the intrusion of the midlatitude eddies and to increase the efficiency of the WES feedback in the subtropical Pacific. Figure 4 shows the changes of mean zonal winds among the three periods averaged across the Pacific $\left(120^{\circ} \mathrm{E}-90^{\circ} \mathrm{W}\right)$. The change from period I to II (Fig. 4a; indicated by the color shadings) is characterized by positive anomalies centered around $30^{\circ} \mathrm{N}$ that coincide with the location of the climatological jet stream (indicated by the contours), while the change from period II to III (Fig. 4b) is characterized by positive and negative anomalies to the north and south of the climatological jet stream, respectively. They indicate that the jet stream location did not change much from period I to II but shifted northward from period II to III. The northward shift in period III can reduce the possible intrusion of the midlatitude eddies into the subtropical Pacific, which enables the WES feedback to operate more efficiently in the region. This is another possible reason that the subtropical coupling and the PMM strength got intensified during period III.
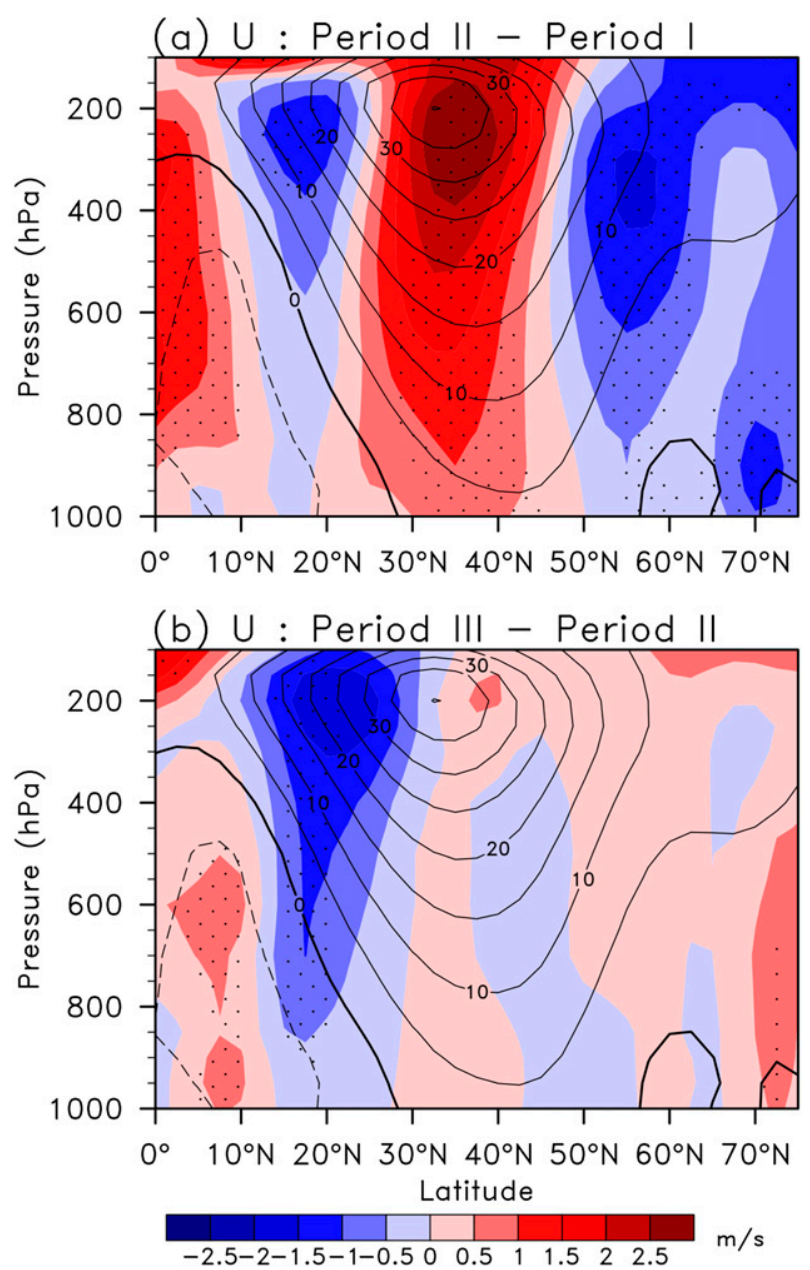

FIG. 4. (a) The difference (color shading) in the DJFMAM-mean zonal winds averaged over $120^{\circ} \mathrm{E}-90^{\circ} \mathrm{W}$ between periods II and I. The climatology is shown in contours with an interval of $5 \mathrm{~m} \mathrm{~s}^{-1}$. Solid (dashed) contours indicate eastward (westward) winds. The dotted areas are where the wind differences are significant at the $95 \%$ level. (b) As in (a), but for the difference between periods III and II.

We next investigated what could be the cause for the intensification of the Pacific subtropical high around the early 1990s? On decadal time scales, the PDO and AMO are two major modes of variability that are capable of influencing global climate. Here, we explored the possible connections between them and the early-1990s strengthening of the Pacific subtropical high. Figures 2d,e show the winter-spring SLP and wind anomalies regressed onto the decadal ( $>10 \mathrm{yr}$ ) components of the PDO and AMO indices. The largest regression with the PDO (Fig. 2d) occurs over the Aleutian low with negative values, which indicates that a positive phase of the PDO is associated with an intensification of the Aleutian low. This regression pattern is similar to the mean SLP change observed from period I to II (cf. Fig. 2b). As for 
the AMO, the regressed SLP anomalies (Fig. 2e) are largest in the regions of the Aleutian low and the subtropical high with positive values. The regression indicates that a positive phase of the AMO is associated with a weakening of the Aleutian low and an intensification of the subtropical high. This regression pattern is similar to the mean SLP change observed from period II to III (cf. Fig. 2c). In particular, the SLP change associated with the AMO also shows a clear northeastsouthwest orientation (highlighted by the red dashed line in Fig. 2e) similar to the orientation of the SLP changes in Fig. 2c. Therefore, the intensification of the subtropical high during the early 1990s can be related to a phase change of the AMO.

The linkage between the early-1990s strengthening of the PMM intensity and the AMO can also be demonstrated in Fig. $1 \mathrm{~b}$ by adding the phase information for the PDO and AMO into the figure. The figure shows that the PDO switched from a negative phase (blue) to a positive phase (red) around 1976, which is the year that separates periods I and II. As for the AMO, its phase switch occurred around 1995, which is close to the year 1993 that separates periods II and III. In period III, the AMO switched to a positive phase, during which the subtropical high should be intensified according to the regression analysis (Fig. 2e). This analysis indicates that the strengthening of the PMM intensity during the early 1990s is closely linked to a phase change in the AMO. As for the phase change of the PDO around 1976, it does not show a significant impact on the PMM intensity. This is likely because the PDO phase change primarily affects the strength of the Aleutian low, which does not produce a strong impact on the subtropical Pacific coupling.

The possible influence of the AMO on the Pacific subtropical high was further examined with 25 AMIP model simulations, where observational SSTs are prescribed from 1979 to 2010 to force AGCMs. Figure 5 shows the changes in the simulated mean SLPs between periods III and II. During these two periods, the AMO changed the phase from a negative to a positive in early 1990s while the PDO maintained its positive phase. Therefore, the analysis of the model output can reveal more concerning the influence of the AMO than that of the PDO. To remove the possible contribution from internal variability to the two-period difference, we used the ensembles for each of the model simulations and averaged across individual members of the same model. We find from Fig. 5 that two AMIP models (MPI-ESMMR and CMCC-CM) produce distinct SLP changes near Aleutian low and subtropical high that are very similar to those found in observations. The next 13 models (BCCCSM1.1 to IPSL-CM5A-MR) in the figure produce a band of positive SLP differences extending from the North Pacific to eastern subtropical Pacific. The positive SLP differences in the subtropical Pacific penetrate well into the PMM region enclosed by the green contours. The last 10 models (ACCESS1.0 to NorESM1-M) of the figure simulate a similar pattern of the SLP differences to the previous group of models but with smaller magnitudes of SLP changes in the subtropical Pacific. Therefore, a majority (15 out of 25 ) of the AMIP models analyzed here produces an intensification of the subtropical high from period II to III. As indicated by the multimodel mean shown in the last panel of Fig. 5, positive SLP changes occur significantly in the subtropical Pacific (i.e., the west of the Baja California) that extend southwestward (i.e., northeast-southwest orientation) to the tropical central Pacific. Based on these results, it is reasonable to state that the AMO intensification of the Pacific subtropical high can be confirmed by AGCM simulations, although the magnitude of the impact is underestimated.

Therefore, it is useful to couple an AGCM to a slab ocean model to further examine the impact of the AMO on tropical Pacific SST variability. We chose to use the NCAR Community Atmospheric Model, version 3 (CAM3; Collins et al. 2006) coupled to a mixed-layer slab ocean model for these experiments. Two experiments were conducted: an AMO positive-phase run and an AMO negative-phase run, in which SSTs corresponding to the positive and negative phases of the AMO, respectively, were prescribed over the North Atlantic $\left(0^{\circ}-70^{\circ} \mathrm{N}\right)$. SSTs in other regions were predicted using the slab ocean model. The prescribed North Atlantic SSTs were constructed by adding (subtracting) SST anomalies associated with the positive (negative) phase of the AMO to the climatological SSTs. The SST anomalies are defined as the regressed SST pattern onto the AMO index (Fig. 6a) multiplied by a factor of 4 . The factor is used to insure that the model produces a strong and clear enough response over the Pacific to the SST forcing associated with the AMO. The model was integrated for $120 \mathrm{yr}$ for each run and only the last $100 \mathrm{yr}$ were used for analysis.

Similar to most of the AMIP simulations, the SLP differences between the two experiments (Fig. 6c) are characterized by a band of positive values extending from high latitudes in the central Pacific to the eastern Pacific subtropics. It is encouraging that the northeastsouthwest extension of the positive SLP differences can also be found in the eastern subtropical Pacific that coincides with the location of the PMM of the coupled model. The PMM strength (i.e., the correlation coefficient between the PMM SST and wind indices) during boreal spring is larger in the AMO positive-phase run (0.94), which has stronger background trade winds, 

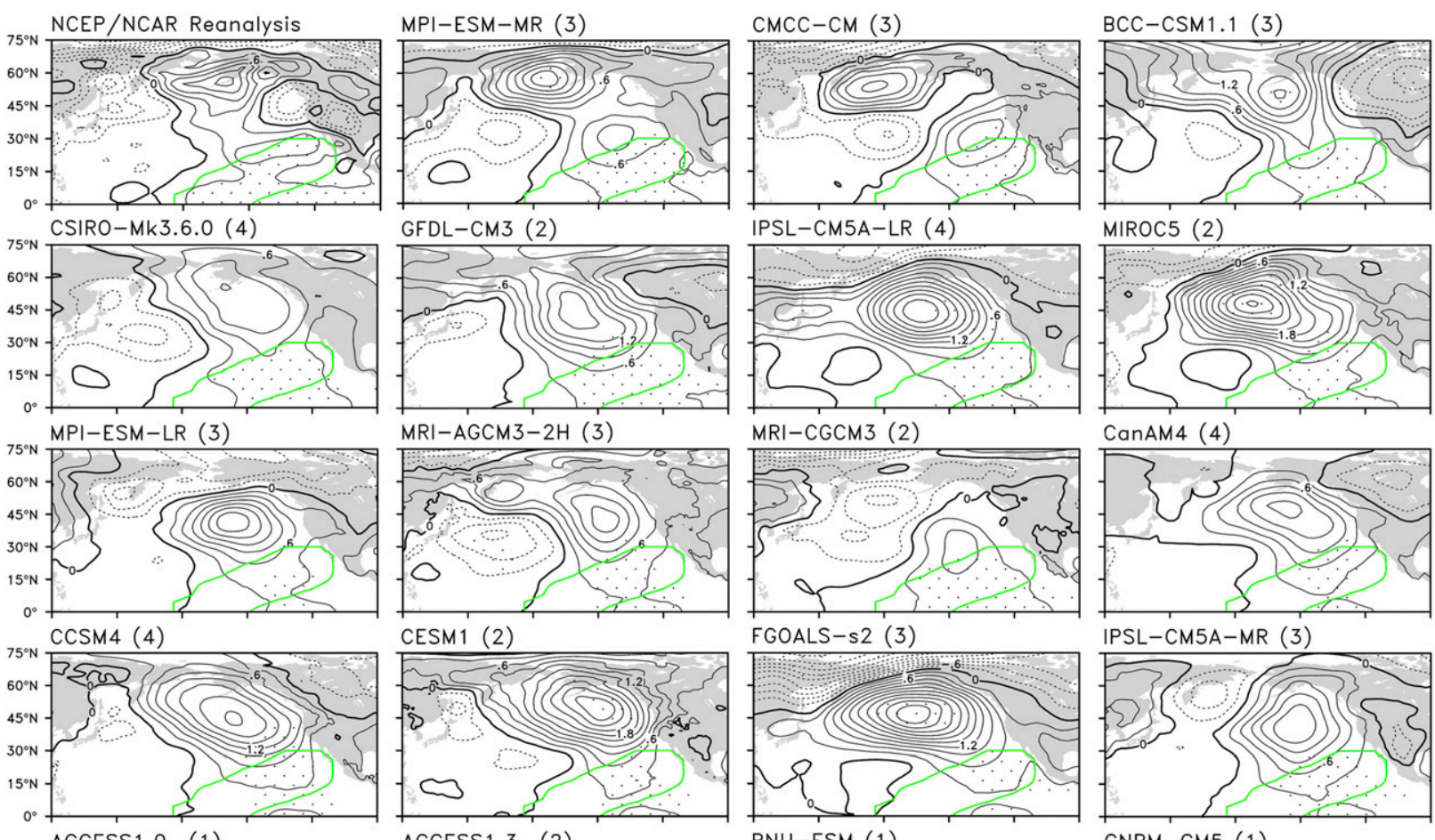

MIROC5 (2)
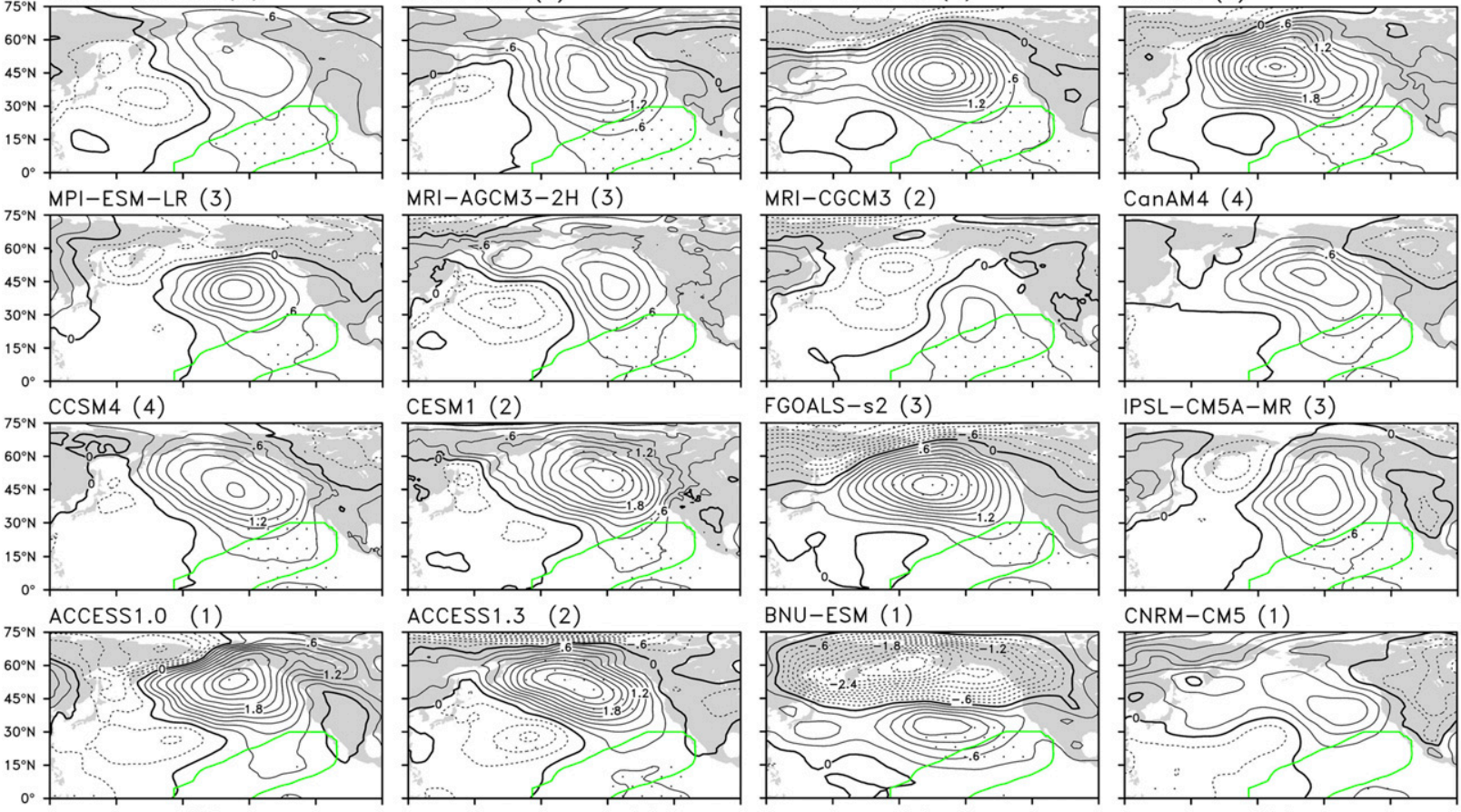

CanAM4 (4)

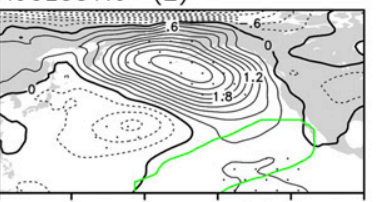

BNU-ESM (1)

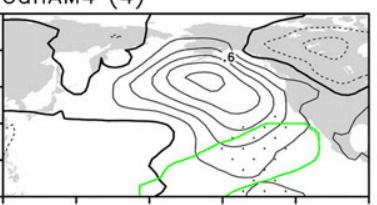

IPSL-CM5A-MR (3)
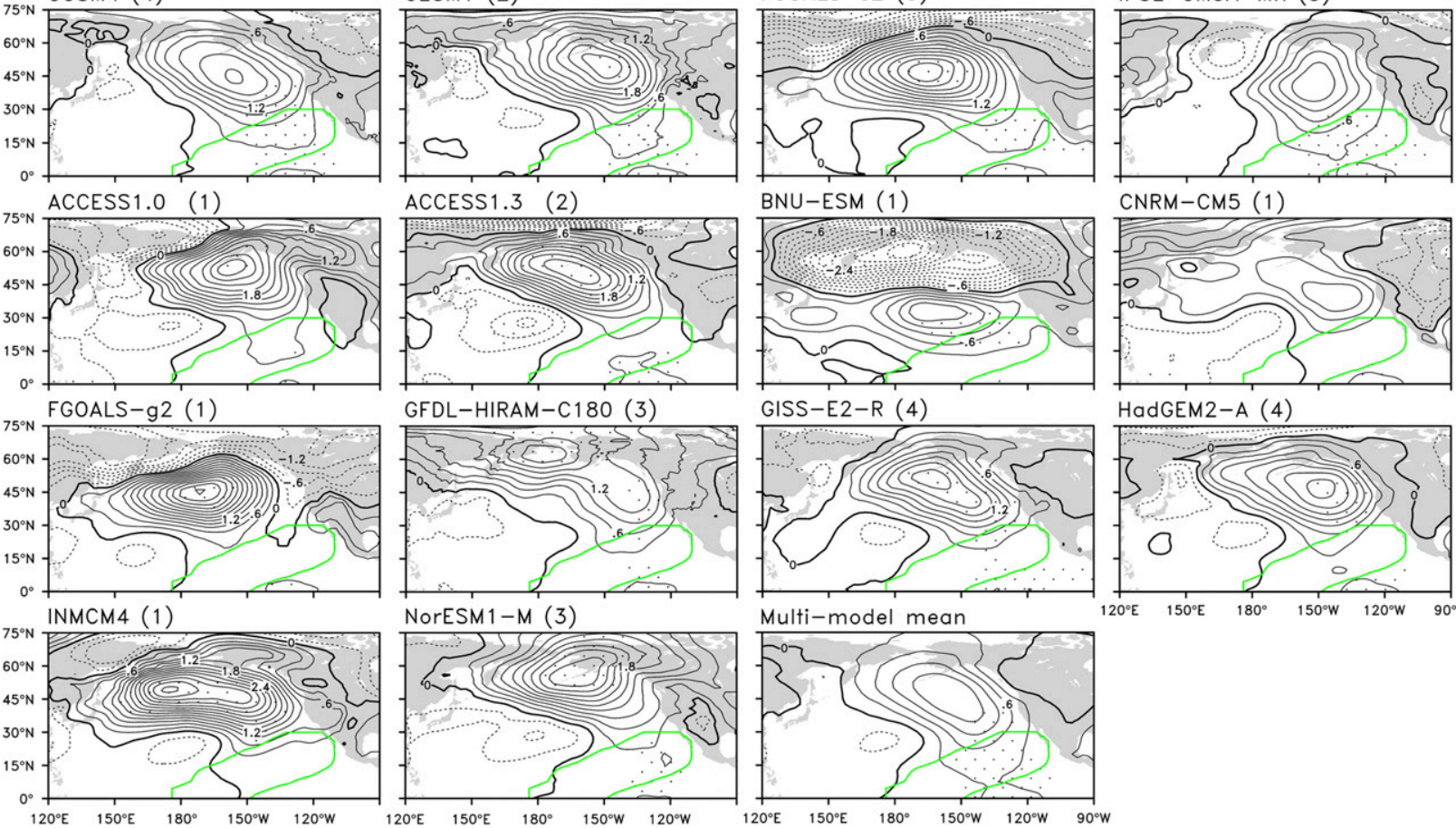

CNRM-CM5 (1)

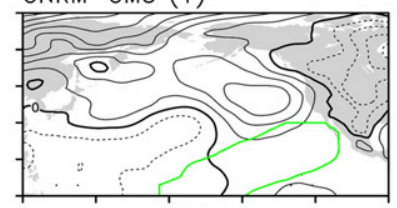

HadGEM2-A (4)

Multi-model mean

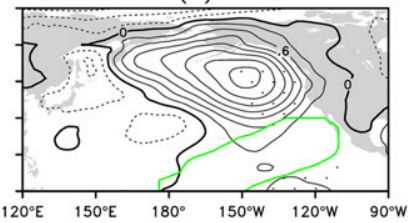

FIG. 5. The differences of the DJFMAM-mean SLP between period III (1993-2004) and period II (1979-88) from 25 AMIP models and NCEP-NCAR reanalysis. The model name is indicated at the top of each panel with the number of ensemble members used in brackets. Solid (dashed) contours indicate positive (negative) differences with an interval of $0.3 \mathrm{hPa}$. The dotted areas are where SLP differences are significant at the $95 \%$ level. The green contour represents the PMM region.

than in the AMO negative-phase run (0.88), which has weaker background trade winds. The strength difference passes the $99 \%$ confidence level using a two-tailed Student's $t$ test. We then compared the interannual SST variability between the two runs along the equator (the standard deviation of the averaged SST anomalies over $5^{\circ} \mathrm{S}-5^{\circ} \mathrm{N}$ ) during boreal winter [December-February (DJF)], when El Niño typically peaks. We found the largest difference occurs in the central Pacific, where the variability in the AMO positive-phase run is almost double that in the AMO negative-phase run (Fig. 6d). Therefore, this set of the coupled model experiments confirms a switch of the AMO to its positive phase can lead to an increase of SST variability in the tropical central Pacific and increase the occurrence of the $\mathrm{CP}$ El Niño. 
(a) AMO pattern

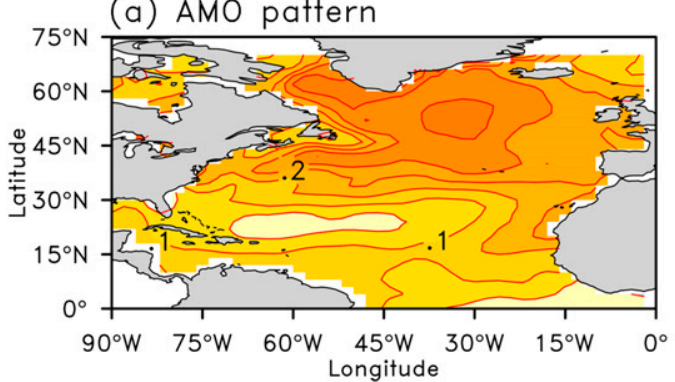

(c) CAM3: SLP \& U

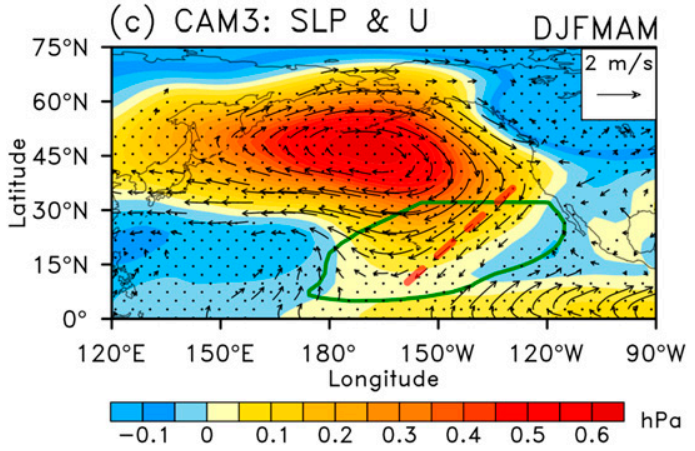

(b) CAM3: SLP clim.
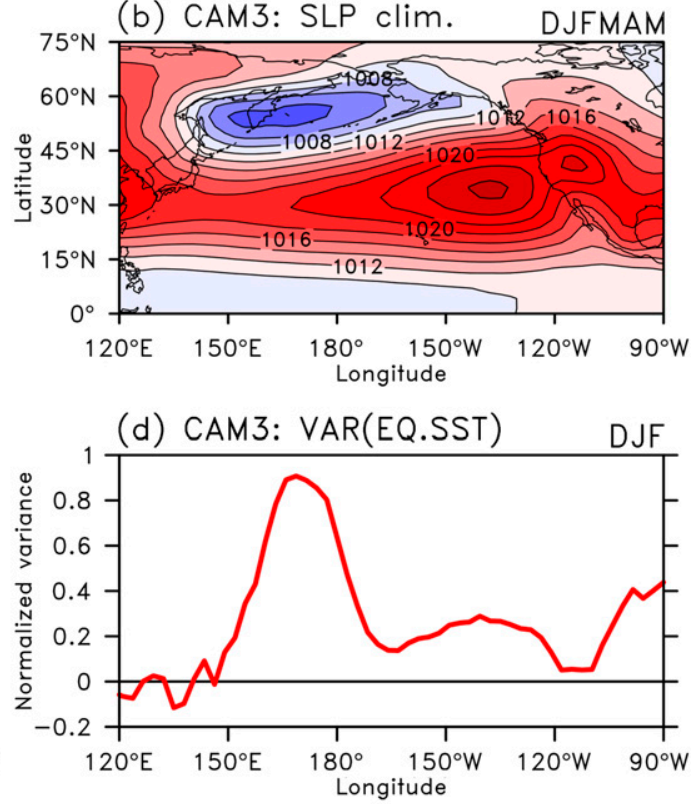

FIG. 6. (a) The regressed SST anomalies over the North Atlantic onto the 10-yr low-pass-filtered standardized AMO index, which were used to force an AMO positive-phase run. The contour interval is $0.1^{\circ} \mathrm{C}$. (b) As in Fig. 2a but for the simulated climatology using CAM3 slab ocean model. (c) As in Fig. 2c, but for the differences between the AMO positive- and negative-phase runs. The green contour denotes the model PMM region. The red dashed line highlights a northeast-southwest extension of the positive SLP difference and enhanced trade winds. (d) The difference in the equatorial Pacific SST variability (the standard deviation) in winter (DJF) between the two AMO runs, normalized by that of the AMO negative-phase run.

\section{Summary and discussion}

The recent shift of El Niño location has posed an interesting challenge to existing theories of El Niño, caused several unexpected changes in global weather and climate patterns, and stirred intense activity in the climate research community (Capotondi et al. 2013). Analyzing observational data and numerical experiments, we showed here that the recent emergence of the CP El Niño can at least partly be attributed to an AMO phase change via the following chain of events: A switch in the AMO to its positive phase in the early 1990s led to an intensification of the Pacific subtropical high. The intensified high resulted in stronger-than-average background trade winds that enhanced the WES feedback mechanism, strengthening the subtropical Pacific coupling between the atmosphere and ocean and ultimately leading to increased interannual SST variability in the equatorial central Pacific. Thus, the shift in El Niño to the CP type in recent decades can be understood as a Pacific Ocean response to a phase change in the AMO. Further understandings of the interbasin interactions involved in this response will help improve climate predictions in the Pacific.

This study does not identify the specific physical processes that enable the AMO to influence the strength of the Pacific subtropical high. Nevertheless, previous studies have offered clues on the possible processes for the influence. Zhang and Delworth (2007), for example, suggested an atmospheric teleconnection between the North Pacific and the AMO using coupled model simulations. During the positive AMO phase, the midlatitude storm track is weakened over the North Pacific and Atlantic in response to the northward oceanic heat transport, which can lead to a poleward shift of the midlatitude jet stream. The mass redistribution associated with this displacement of the jet stream may affect the strength of the subtropical high. Another important issue not addressed in this study is the cause of the breakdown of the PMM strength around the mid-1970s and early 1990s, when the PDO and AMO changed their phases. It is possible that the atmospheric and oceanic fields are less correlated when the Pacific mean state was rapidly adjusting from one climate regime to the other during the phase transition of the PDO or AMO. Further investigations are needed to better understand these two important issues.

Acknowledgments. This research was supported by NSF Grant AGS-1233542 and NOAA-MAPP Grant NA11OAR4310102. We thank two anonymous reviewers and editor Kerry Cook for their valuable comments, 
Shang-Ping Xie of UCSD for the very helpful discussion on the WES feedback mechanism, and Sang-Ki Lee of NOAA for kindly providing us with the modified code for CAM3. The NCEP-NCAR reanalysis, 20CR, and ERSST datasets and the indices for the PDO and AMO were downloaded from the NOAA/ESRL/PSD web archive (http://www.esrl.noaa.gov/psd) and JRA-55 data are from the NCAR CISL Research Data Archive (http:// rda.ucar.edu/datasets/ds628.1). The AMIP model output was obtained from the CMIP5 data archive (http:// pcmdi9.1lnl.gov).

\section{REFERENCES}

Alexander, M., and Coauthors, 2006: Extratropical atmosphereocean variability in CCSM3. J. Climate, 19, 2496-2525, doi:10.1175/JCLI3743.1.

- D. J. Vimont, P. Chang, and J. D. Scott, 2010: The impact of extratropical atmospheric variability on ENSO: Testing the seasonal footprinting mechanism using coupled model experiments. J. Climate, 23, 2885-2901, doi:10.1175/ 2010JCLI3205.1.

Anderson, B. T., 2003: Tropical Pacific sea-surface temperatures and preceding sea level pressure anomalies in the subtropical North Pacific. J. Geophys. Res., 108, 4732, doi:10.1029/ 2003JD003805.

Ashok, K., S. Behera, A. S. Rao, H. Weng, and T. Yamagata, 2007: El Niño Modoki and its teleconnection. J. Geophys. Res., 112, C11007, doi:10.1029/2006JC003798.

Battisti, D. S., and A. C. Hirst, 1989: Interannual variability in the tropical atmosphere-ocean model: Influence of the basic state, ocean geometry and nonlinearity. J. Atmos. Sci., 46, 1687-1712, doi:10.1175/1520-0469(1989)046< <1687:IVIATA > 2.0.CO;2.

Bretherton, C. S., C. Smith, and J. M. Wallace, 1992: An intercomparison of methods for finding coupled patterns in climate data. J. Climate, 5, 541-560, doi:10.1175/1520-0442(1992)005<0541: $\mathrm{AIOMFF}>2.0 . \mathrm{CO} ; 2$.

Capotondi, A., and Coauthors, 2013: U.S. CLIVAR ENSO Diversity Workshop report. U.S. CLIVAR Rep. 2013-1, 23 pp.

Chang, P., L. Zhang, R. Saravanan, D. J. Vimont, J. C. H. Chiang, L. Ji, H. Seidel, and M. K. Tippett, 2007: Pacific meridional mode and El Niño-Southern Oscillation. Geophys. Res. Lett., 34, L16608, doi:10.1029/2007GL030302.

Chiang, J. C. H., and D. J. Vimont, 2004: Analogous Pacific and Atlantic meridional modes of tropical atmosphere-ocean variability. J. Climate, 17, 4143-4158, doi:10.1175/JCLI4953.1.

Collins, W. D., and Coauthors, 2006: The formulation and atmospheric simulation of the Community Atmosphere Model version 3 (CAM3). J. Climate, 19, 2144-2161, doi:10.1175/JCLI3760.1.

Compo, G. P., and P. D. Sardeshmukh, 2010: Removing ENSOrelated variations from the climate record. J. Climate, 23, 1957-1978, doi:10.1175/2009JCLI2735.1.

_ , and Coauthors, 2011: The Twentieth Century Reanalysis project. Quart. J. Roy. Meteor. Soc., 137, 1-28, doi:10.1002/qj.776.

Czaja, A., P. van der Vaart, and J. Marshall, 2002: A diagnostic study of the role of remote forcing in tropical Atlantic variability. J. Climate, 15, 3280-3290, doi:10.1175/1520-0442(2002)015<3280: ADSOTR $>2.0 . \mathrm{CO} ; 2$.

Ebita, A., and Coauthors, 2011: The Japanese 55-year Reanalysis "JRA-55": An interim report. SOLA, 7,149-152, doi:10.2151/ sola.2011-038.
Enfield, D. B., A. M. Mestas-Nuñez, and P. J. Trimble, 2001: The Atlantic multidecadal oscillation and its relation to rainfall and river flows in the continental US. Geophys. Res. Lett., 28, 2077-2080, doi:10.1029/2000GL012745.

Gates, W. L., and Coauthors, 1999: An overview of the results of the Atmospheric Model Intercomparison Project (AMIP I). Bull. Amer. Meteor. Soc., 80, 29-55, doi:10.1175/ 1520-0477(1999)080<0029:AOOTRO > 2.0.CO;2.

Jin, F.-F., 1997: An equatorial recharge paradigm for ENSO. Part I: Conceptual model. J. Atmos. Sci., 54, 811-829, doi:10.1175/ 1520-0469(1997)054<0811:AEORPF > 2.0.CO;2.

Kalnay, E., and Coauthors, 1996: The NCEP/NCAR 40-Year Reanalysis Project. Bull. Amer. Meteor. Soc., 77, 437-471, doi:10.1175/1520-0477(1996)077<0437:TNYRP>2.0.CO;2.

Kao, H.-Y., and J.-Y. Yu, 2009: Contrasting eastern Pacific and central Pacific types of ENSO. J. Climate, 22, 615-632, doi:10.1175/2008JCLI2309.1.

Kerr, R. A., 2000: A North Atlantic climate pacemaker for the centuries. Science, 288, 1984-1986, doi:10.1126/science.288.5473.1984.

Kim, S. T., J.-Y. Yu, A. Kumar, and H. Wang, 2012: Examination of the two types of ENSO in the NCEP CFS model and its extratropical associations. Mon. Wea. Rev., 140, 1908-1923, doi:10.1175/MWR-D-11-00300.1.

Kug, J.-S., F.-F. Jin, and S.-I. An, 2009: Two types of El Niño events: Cold tongue El Niño and warm pool El Niño. J. Climate, 22, 1499-1515, doi:10.1175/2008JCLI2624.1.

Larkin, N. K., and D. E. Harrison, 2005: On the definition of El Niño and associated seasonal average U.S. weather anomalies. Geophys. Res. Lett., 32, L13705, doi:10.1029/2005GL022738.

Lee, T., and M. J. McPhaden, 2010: Increasing intensity of El Niño in the central-equatorial Pacific. Geophys. Res. Lett., 37, L14603, doi:10.1029/2010GL044007.

Lin, C.-Y., J.-Y. Yu, and H. H. Hsu, 2014: CMIP5 model simulations of the Pacific meridional mode and its connection to the two types of ENSO. Int. J. Climatol., doi:10.1002/joc.4130, in press.

Mantua, N. J., S. R. Hare, Y. Zhang, J. M. Wallace, and R. C. Francis, 1997: A Pacific decadal climate oscillation with impacts on salmon production. Bull. Amer. Meteor. Soc., 78, 1069-1079, doi:10.1175/1520-0477(1997)078<1069: APICOW $>2.0 . \mathrm{CO} ; 2$.

McPhaden, M. J., T. Lee, and D. McClurg, 2011: El Niño and its relationship to changing background conditions in the tropical Pacific Ocean. Geophys. Res. Lett., 38, L15709, doi:10.1029/ 2011GL048275.

Newman, M., S.-I. Shin, and M. A. Alexander, 2011: Natural variation in ENSO flavors. Geophys. Res. Lett., 38, L14705, doi:10.1029/2011GL047658.

Rogers, J. C., 1981: The North Pacific Oscillation. J. Climatol., 1, 39-57, doi:10.1002/joc.3370010106.

Schlesinger, M. E., and N. Ramankutty, 1994: An oscillation in the global climate system of period $65-70$ years. Nature, 367, 723 726, doi:10.1038/367723a0.

Smith, T. M., R. W. Reynolds, T. C. Peterson, and J. Lawrimore, 2008: Improvements to NOAA's historical merged landocean surface temperature analysis (1880-2006). J. Climate, 21, 2283-2296, doi:10.1175/2007JCLI2100.1.

Solomon, A., and M. Newman, 2012: Reconciling disparate twentieth-century Indo-Pacific Ocean temperature trends in the instrumental record. Nat. Climate Change, 2, 691-699, doi:10.1038/nclimate1591.

Suarez, M. J., and P. S. Schopf, 1988: A delayed action oscillator for ENSO. J. Atmos. Sci., 45, 3283-3287, doi:10.1175/ 1520-0469(1988)045<3283:ADAOFE >2.0.CO;2. 
Taylor, K. E., R. J. Stouffer, and G. A. Meehl, 2012: An overview of CMIP5 and the experiment design. Bull. Amer. Meteor. Soc., 93, 485-498, doi:10.1175/BAMS-D-11-00094.1.

Vimont, D. J., D. S. Battisti, and A. C. Hirst, 2001: Footprinting: A seasonal connection between the tropics and midlatitudes. Geophys. Res. Lett., 28, 3923-3926, doi:10.1029/ 2001 GL013435.

- J. M. Wallace, and D. S. Battisti, 2003: The seasonal footprinting mechanism in the Pacific: Implications for ENSO. J. Climate, 16, 2668-2675, doi:10.1175/1520-0442(2003)016<2668: TSFMIT $>2.0 . \mathrm{CO} ; 2$.

— M. Alexander, and A. Fontaine, 2009: Midlatitude excitation of tropical variability in the Pacific: The role of thermodynamic coupling and seasonality. J. Climate, 22, 518-534, doi:10.1175/2008JCLI2220.1.

Walker, G. T., and E. W. Bliss, 1932: World weather V. Mem. R. Meteor. Soc., 4, 53-84.

Xie, S.-P., 1999: A dynamic ocean-atmosphere model of the tropical Atlantic decadal variability. J. Climate, 12, 64-70, doi:10.1175/1520-0442-12.1.64.

__ and S. G. H. Philander, 1994: A coupled ocean-atmosphere model of relevance to the ITCZ in the eastern Pacific. Tellus, 46A, 340-350, doi:10.1034/j.1600-0870.1994.t01-1-00001.x.

Yeh, S. W., J. S. Kug, B. Dewitte, M. H. Kwon, B. P. Kirtman, and F.-F. Jin, 2009: El Niño in a changing climate. Nature, 461, 511514, doi:10.1038/nature08316.
Yu, J.-Y., and H.-Y. Kao, 2007: Decadal changes of ENSO persistence barrier in SST and ocean heat content indices: 1958-2001. J. Geophys. Res., 112, D13106, doi:10.1029/2006JD007654.

— , and S. T. Kim, 2011: Relationships between extratropical sea level pressure variations and the central Pacific and eastern Pacific types of ENSO. J. Climate, 24, 708-720, doi:10.1175/ 2010JCLI3688.1.

—, and B. S. Giese, 2013: ENSO diversity in observations. CLIVAR Variations, Vol. 11, No. 2, U.S. CLIVAR, Washington, DC, $1-5$.

—, H.-Y. Kao, and T. Lee, 2010: Subtropics-related interannual sea surface temperature variability in the central equatorial Pacific. J. Climate, 23, 2869-2884, doi:10.1175/ 2010JCLI3171.1.

,,--- , and S. T. Kim, 2011: Subsurface ocean temperature indices for central-Pacific and eastern-Pacific types of El Niño and La Niña events. Theor. Appl. Climatol., 103, 337344, doi:10.1007/s00704-010-0307-6.

—, M.-M. Lu, and S. T. Kim, 2012: A change in the relationship between tropical central Pacific SST variability and the extratropical atmosphere around 1990. Environ. Res. Lett., 7, 034025, doi:10.1088/1748-9326/7/3/034025.

Zhang, R., and T. L. Delworth, 2007: Impact of the Atlantic multidecadal oscillation on North Pacific climate variability. Geophys. Res. Lett., 34, L23708, doi:10.1029/ 2007GL031601. 